\title{
Sexual Function and Socio-Sexual Difficulties in Women with Polycystic Ovary Syndrome (PCOS)
}

\section{Sexualfunktion und soziosexuelle Schwierigkeiten bei Frauen mit polyzystischem Ovarsyndrom (PCOS)}

\section{(우(1) (요 $\ominus$}

Authors

Maike Fliegner, Hertha Richter-Appelt, Kerstin Krupp, Franziska Brunner

Affiliation

Institut für Sexualforschung und Forensische Psychiatrie, Universitätsklinikum Hamburg-Eppendorf, Hamburg, Germany

Key words

polycystic ovary syndrome, sexual quality of life, feelings of inadequacy in social and sexual situations, depression, hirsutism

\section{Schlüsselwörter}

polyzystisches Ovarsyndrom, sexuelle Lebensqualität, Unsicherheit in sexuellen Situationen, Depression, Hirsutismus

received $\quad 4.11 .2018$

revised 23.12.2018

accepted 2.1.2019

Bibliography

DOI https://doi.org/10.1055/a-0828-7901

Geburtsh Frauenheilk 2019; 79: 498-509 @ Georg Thieme

Verlag KG Stuttgart · New York | ISSN 0016-5751

Correspondence

Dr. Franziska Brunner

Universitätsklinikum Hamburg-Eppendorf, Institut

für Sexualforschung und Forensische Psychiatrie

Martinistraße 52, 20246 Hamburg, Germany

f.brunner@uke.de

\section{ABSTRACT}

Introduction PCOS is the most common endocrine syndrome in women of the reproductive age that has manifold effects on the life of affected women. Little scientific attention has been devoted to these women's sexual lives.

Aim To investigate sexual quality of life in women with PCOS. Methods The sample size was $n=44$. Measures employed were: An extended list of sexual dysfunctions and perceived distress based on DSM-IV-TR, Female Sexual Function Index (FSFI), German Questionnaire on Feelings of Inadequacy in
Social and Sexual Situations (FUSS), Rosenberg Self-Esteem Scale (RSE), Brief Symptom Inventory (BSI) subscale depression. The relationships of these components were examined including further variables (body mass index, degree of hirsutism using the Ferriman-Gallwey Score, wish for a child). An open question about what participants see as the source of their sexual problems was presented.

Results Only moderate impairment in sexual function was detected, but feelings of inadequacy in social and sexual situations were markedly elevated and positively correlated with the degree of hirsutism. Depression showed to be a major problem.

Conclusion Patients with PCOS should be screened for sociosexual difficulties and emotional problems. Specialized psychological and sexological counselling can complement patient care.

\section{ZUSAMMENFASSUNG}

Einleitung PCOS ist die häufigste endokrine Störung bei Frauen im gebärfähigen Alter und kann vielfältige Auswirkungen auf das Leben betroffener Frauen haben. Bislang wurde dem Sexualleben von betroffenen Frauen wenig Aufmerksamkeit gewidmet.

Ziel Ziel dieser Studie war es, die sexuelle Lebensqualität von Frauen mit PCOS zu untersuchen.

Methoden Die Fallzahl betrug $n=44$. Folgende Fragebogen wurden zur Untersuchung verschiedenster Aspekte herangezogen: Sexualstörungen und subjektiv wahrgenommenes Leiden basierend auf dem DSM-IV-TR, dem Female Sexual Function Index (FSFI), dem Fragebogen zur Unsicherheit in sexuellen Situationsen (FUSS), der Rosenberg Self-Esteem Scale (RSE), der Subskala Depressivität des Brief Symptom Inventory (BSI). Die Beziehungen der verschiedenen Aspekte untereinander wurden zusammen mit weiteren Variablen (BodyMass-Index, Ausmaß des Hirsutismus gemessen mit dem Ferriman-Gallwey-Score, Kinderwunsch) untersucht. Den Teilnehmerinnen wurde ein offener Fragenbogen vorgelegt, in dem sie sich darüber äußern sollten, was sie als die Ursache ihrer Sexualprobleme betrachteten. 
Ergebnisse Während die Sexualfunktion nur moderat beeinträchtigt war, waren Unsicherheitsgefühle in soziosexuellen Situationen signifkant erhöht und korrelierten positiv mit dem Ausmaß des Hirsutismus. Es zeigte sich, dass Depression ein erhebliches Problem darstellte.
Schlussfolgerung Patientinnen mit PCOS sollten auf soziosexuelle Schwierigkeiten und emotionalen Probleme untersucht werden. Eine zielgerichtete psychologische Beratung sowie eine Sexualberatung könnten eine sinnvolle Ergänzung der Patientinnenversorgung sein.

\section{Introduction}

Sexuality has a high impact on the overall well-being [1]. Sexual quality of life comprises all aspects that result in a satisfying sexuality. That means sexual quality of life is more than the mere absence of an illness or a disorder that might impair sexual functioning. It also involves the ability to fall in love, to initiate and maintain a sexual and romantic relationship and to feel certain about one's own sexuality [2]. A sexual disorder can be an indicator for an impaired sexual quality of life but sexual well-being should be assessed in more detail. Moreover, overall physical functioning, partnership, and the self-worth have been identified to influence sexual quality of life [1,3]. Additionally, the attitude towards the own body, more specific the genitals [4-6] and the body image [7], have an effect on our sexuality.

The most common endocrinopathy amongst women at the reproductive stage [8-11], the polycystic ovary syndrome (PCOS) with a prevalence rate of about $5 \%[12,13]$ or even up to $17.8 \%$ in a community sample [14], is associated with an impaired general quality of life and psychological well-being in affected women [15-22]. However, not much is known about the sexual quality of life of women with PCOS. Most research focuses on sexual function whereby most studies report only global scores (e.g. [2328]) and specific sexual dysfunctions are only sporadically reported [29-33]. So far it appears that sexual satisfaction and sexual self-worth are impaired [16,23, 24, 29, 30,34-37]. More research on sexual quality of life is necessary because PCOS affects a high number of women and is associated with a number of symptoms that each by itself can mediate sexuality.

The syndrome is currently defined as a combination of hyperandrogenism (hirsutism and/or hyperandrogenemia) and ovarian dysfunction (oligo-anovulation and/or polycystic ovaries) (NIH criteria [38]; Rotterdam criteria [39]). Affected women face multiple problems, for example menstrual irregularities or amenorrhea, hirsutism, acne, alopecia and obesity while there is a wide variety in the clinical presentation [40].

Obesity has been documented to have a negative effect on sexuality $[41,42]$, but in women with PCOS the results are mixed [23, 26, 41, 42].

Hirsutism has been described to have aversive effects on sexuality by causing body dissatisfaction and interfering with the women's feminine self-perception [16, 25, 29, 31, 37, 43-47]. Infertility is a burden that can lead to marital problems and sexual dysfunction [48-50]. Barnard et al. found that infertility was the third most troubling symptom of PCOS after weight concerns and menstrual problems [51]. A negative association between the wish for a child and sexual well-being in women with PCOS would thus seem plausible.
Literature on self-esteem and sexuality seems to support a positive relationship between these two variables [3]. Low self-esteem can also adversely affect a person's body image and in this way negatively influence sexuality $[3,52,53]$. Systematic studies on self-esteem in women with PCOS are scarce $[20,30,37,44$, 54]. Depression or more generally mood is a known mediator in female sexual function $[55,56]$. Depression has often been reported to be elevated in women with PCOS [17, 24, 36, 51, 57, 58-60], a negative influence on sexuality in PCOS patients could thus be expected.

\section{Aims}

This study is designed to investigate sexual quality of life in women with polycystic ovary syndrome (PCOS). First, sexual difficulties and perceived distress will be described the level of individual sexual problems as outlined in the DSM-IV-TR of the American Psychiatric Association [61]. The second aim is to explore total sexual function scores, feelings of inadequacy in social and sexual situations as well as to take a look at general self-esteem and depression. Third, the relationships of these variables will be examined linking them to putative mediators such as body mass index, the wish for a child and hirsutism. The study will close with an inquiry about what participants see as the source of their sexual problems.

\section{Materials and Methods}

\section{Procedure}

This cross-sectional study was conducted within the scope of the research project "Androgens, Quality of Life and Femininity in People with Complete Androgen Insensitivity (CAIS), Mayer-Rokitansky-Küster-Hauser Syndrome (MRKHS) and Polycystic Ovary Syndrome (PCOS)" at the University Medical Center Hamburg-Eppendorf, Institute for Sex Research and Forensic Psychiatry. Recruitment of participants was accomplished by contacting support groups and professionals in the field of gynaecology and endocrinology and via an internet announcement.

An extensive paper \& pencil questionnaire was developed which included standardised as well as self-developed scales and open questions. The study employed scales and questions also used in a previously conducted study on intersex conditions - University Medical Center Hamburg-Eppendorf, Institute for Sex Research and Forensic Psychiatry [62-64]. Participants filled out the questionnaire at home or at the research centre. A compensation of 20 EUR was granted. The data were collected between 03/ 2010 and 07/2011. The study was approved of by the ethics committee. 


\section{Participants}

Participants had to be of full legal age ( $\geq 18$ years) and data were included only if informed consent had been given. Diagnostic information was accepted with a differentiation between two levels of confirmation: Participants had to confirm that they had the polycystic ovary syndrome and that they had been diagnosed by a medical doctor. This was considered "second degree confirmation". If consent was given, the attending medical doctors were contacted and asked to verify the diagnosis and send in medical records. Diagnoses attested directly by doctors were considered "first degree confirmation".

\section{Outcome measures}

\section{Sexual problems and dysfunctions}

A list of sexual problems was presented. It was developed based on DSM-IV-TR diagnoses [61], but extended to include further problems [62]. First, participants had to indicate whether the respective situation was true for them ("yes" or "no") and then, whether this problem caused them distress ("yes" or "no"). A mean number of sexual problems was calculated (maximum: 12).

Comparison data were available from a previous study by the authors [65]. Sexual problems that required previous sexual experience were only analysed in experienced individuals.

\section{Standardised scales}

All scores were calculated according to the manuals. For all scales satisfactory to excellent psychometric properties are reported [65-69].

\section{Female Sexual Function Index (FSFI)}

The Female Sexual Function Index $[66,70]$ is a self-report scale used to assess sexual function in women during the past four weeks. Full-scale scores range from 2.0 to 36.0, with high numbers indicating better sexual function. Comparison data were available from the publication by Rosen [66]. Full-scale scores have been classified as "poor" when $\leq 23$, as "good" or "satisfactory" when within the range of 24-29, and as "very good" when $\geq 30[71,72]$.

Feelings of Inadequacy in Social and Sexual Situations (FUSS) The questionnaire by Fahrner assesses feelings of inadequacy during interactions with a potential or an actual romantic partner [73]. It contains two subscales: "social" and "sexual". Each subscale consists of 11 statements. Participants indicate their level of agreement ( $0=$ "not at all true" and 5 = "absolutely true"). "I feel anxious when talking to an attractive man/woman" is an example of a social situation that might trigger feelings of inadequacy (FUSS social), "I don't know how to tell a man/woman when I would like to have sex with him/her" refers to insecurity in the sexual domain (FUSS sexual). Comparison data from a healthy control group were available from the publication by Fahrner [73].

\section{Rosenberg Self-Esteem Scale (RSE)}

The Rosenberg Self-Esteem Scale [74] is measure for the assessment of global self-worth $[67,75,76]$. The scale consists of 10 statements scaled 1 ("not true at all") to 4 ("absolutely true"). A high RSE score (max. 40) represents high self-confidence. The current study employed the version by von Collani and Herzberg [68]. Comparison data from a non-clinical sample were available from a publication by Martín-Albo et al. [77].

\section{Brief Symptom Inventory (BSI)}

The Brief Symptom Inventory is a questionnaire on psychological distress by Derogatis and Melisaratos $[69,78]$. It is divided into 9 subscales. In this study only the depression subscale was employed. Original scores are transformed into t-scores according to the manual's norm charts. T-values $\geq 63$ are classified as clinically relevant [69].

\section{Ferriman Gallwey Score (FG)}

Hirsutism was assessed using the modified Ferriman-Gallwey method [79-81] including nine body parts. FG-Scores $\geq 6$ were considered significant hirsutism [12,82].

\section{Wish for a child}

The intensity of the participants' current wish for a child was assessed using a single question: "How much would you currently like to have a child?" The answer was measured on a Likert scale of 1 "not" to 5 "very much".

\section{Open question on alleged cause(s) of sexual problems}

The list of Sexual Problems and Dysfunctions was supplemented by an open question: "If you have any of the sexual problems mentioned above, what do you think is/are the reason(s) for it?"

\section{Statistical methods}

All calculations were conducted using the SPSS software package PASW Statistics 18.0.0.

Categorical data were compared using Pearson's $x^{2}$, when expected frequencies were not adequate Fisher's exact probability test was used instead.

Differences between the PCOS group and comparison samples $[66,73,77]$ were analysed using t-tests (check $>$ Table 2).

Continuous data were categorised in order to find out how many individuals showed critical scores. For both FUSS scales and the RSE scale each individual's score was z-transformed. Scores above +1.64 (FUSS social, FUSS sexual) or below - 1.64 (RSE) were defined as "critical", for in the general population only $5 \%$ of the people would be expected to show scores this extreme. For the FSFI and the BSI depression scale categorisations were already available (see above).

Pearson's correlations were employed to identify relationships between variables.

For better comparability between measures effect sizes were calculated for Mann-Whitney $U$ and t-tests and expressed as correlation coefficient $r$, whereby $r \geq 0.10$ stands for a small, $r \geq 0.30$ for a medium and $r \geq 0.50$ for a large effect [83].

Qualitative data were analysed using Mayring's qualitative content analysis method [84]. Numbers and ratios of participants who mentioned a derived topic are given. Ratios refer to the total number of people who gave an answer to the question. 


\section{Results}

\section{Participants}

Eleven questionnaires had to be discarded at the outset (no informed consent, unclear or missing diagnosis). Of the remaining 55 participants, another eleven were excluded (currently pregnant, recently delivered a baby). A total of 44 data sets could finally be included in the study.

The diagnosis was confirmed by a medical doctor's statement or medical records ("first degree confirmation") for 27 (61.4\%) participants. For the rest 17 (38.6\%) "second degree confirmation" was available. 21 (47.7\%) women were informed about the study by a fertility clinic.

\section{Sample characteristics}

The median age of the participants was 28.5 years $\left(Q_{25}=27.0\right.$, $\left.\mathrm{Q}_{75}=30.8\right)$. The PCOS group showed the following median level of education of $4.0\left(Q_{25}=3.0, Q_{75}=6.0\right)$. A value of 4 corresponds to German "Abitur" which is equivalent to $12-13$ years of schooling. $84.1 \%(n=37)$ reported being in a relationship whereby the partnerships were exclusively heterosexual. The sample's median body mass index (BMI) was $25.8\left(\mathrm{Q}_{25}=21.2, \mathrm{Q}_{75}=32.6\right) .21$ (47.7\%) women had a BMI below 25, eight (18.2\%) participants were overweight (BMI $\geq 25$ to $<30$ ) and 15 (43.1\%) were obese $(\mathrm{BMI} \geq 30$ ).

The participants' current wish for a child was $M d=5.0$ $\left(Q_{25}=3.0, Q_{75}=5.0\right)$ which is the maximum possible value and corresponds to a very strong wish for a child.

Hirsutism as assessed by the modified Ferriman-Gallwey method yielded a median score of $7.5\left(Q_{25}=4.0, Q_{75}=13.75\right)$, with $\mathrm{n}=27(61.4 \%)$ showing relevant hirsutism as defined by a FGscore $\geq 6$ points $[12,82]$.

\section{Descriptive data - PCOS symptoms and sexual experience}

For information on menstruation, acne, greasy hair ("seborrhea") and hair loss ("alopecia") check > Table 1.

43 women (97.7\%) indicated having had sexual intercourse at least once in a lifetime, 38 women $(86.4 \%)$ reported having masturbated in the past. 41 of the women (93.2\%) reported orgasm experience. Median age at first intercourse was 17.5 years $\left(Q_{25}=16.0, Q_{75}=20.0\right)$, median age at first masturbation was 14.0 years $\left(Q_{25}=13.0, Q_{75}=16.5\right)$. Satisfaction with sex life was a median of $3.0\left(Q_{25}=2.0, Q_{75}=4.0\right)$ which stands for "moderately satisfied", the item scale ranged from 1 ("very dissatisfied") to 5 ("very satisfied"). Please check $>$ Table 1.

\section{Main Results}

\section{Sexual problems and dysfunctions}

No differences were observed between PCOS and a non-clinical convenience sample (data were collected in a previous study, see [65]) regarding sexual problem rates. For an overview of sexual problem rates and distress see $\mathbf{- F i g .} \mathbf{1}$.

The PCOS group and the control sample did not differ significantly in terms of the number of sexual problems (Mann-Whitney $U=2479.5, p=0.673, r=-0.03$; PCOS: $M d=2.0, Q_{25}-Q_{75}=0.00-$
- Table 1 Descriptive data - PCOS symptoms and sexual experience.

\begin{tabular}{|c|c|}
\hline \multirow[t]{2}{*}{ Variables } & $\begin{array}{l}\text { PCOS } \\
n=44\end{array}$ \\
\hline & $\mathrm{n}(\%)^{1}$ \\
\hline \multicolumn{2}{|l|}{ Menstruation } \\
\hline - irregular & $14(31.8)$ \\
\hline - menstruation under hormone therapy & $27(61.4)$ \\
\hline - irregular even under hormone therapy & $3(6.8)$ \\
\hline \multicolumn{2}{|l|}{ Acne } \\
\hline - yes & $17(38.6)$ \\
\hline - no & $25(56.8)$ \\
\hline - missing & $2(4.5)$ \\
\hline \multicolumn{2}{|l|}{ Greasy hair } \\
\hline - yes & $24(54.5)$ \\
\hline - no & $19(43.2)$ \\
\hline - missing & $1(2.3)$ \\
\hline \multicolumn{2}{|l|}{ Hair loss } \\
\hline - yes & $7(15.9)$ \\
\hline " no & $33(75.0)$ \\
\hline " missing & $4(9.1)$ \\
\hline \multicolumn{2}{|l|}{ Intercourse experience } \\
\hline - yes & $43(97.7)$ \\
\hline " no & $1(2.3)$ \\
\hline - missing & - \\
\hline \multicolumn{2}{|l|}{ Masturbation experience } \\
\hline " yes & $38(86.4)$ \\
\hline - no & $6(13.6)$ \\
\hline - missing & - \\
\hline \multicolumn{2}{|l|}{ Orgasm experience } \\
\hline - yes & $41(93.2)$ \\
\hline - no & - \\
\hline \multirow[t]{2}{*}{ - missing } & $3(6.8)$ \\
\hline & $\begin{array}{l}\operatorname{Mdn}\left(Q_{25}-Q_{75}\right) \\
\text { Range }\end{array}$ \\
\hline Age at first intercourse (yrs.) & $\begin{array}{l}17.5(16.0-20.0) \\
13.0-30.0\end{array}$ \\
\hline - missing & $\mathrm{n}=2(4.5 \%)$ \\
\hline Age at first masturbation (yrs.) & $\begin{array}{l}14.0(13.0-16.5) \\
5.0-30.0\end{array}$ \\
\hline - missing & $\mathrm{n}=7(15.9 \%)$ \\
\hline Satisfaction with sex life ${ }^{2}$ & $\begin{array}{l}3.0(2.0-4.0) \\
1.0-5.0\end{array}$ \\
\hline - missing & $\mathrm{n}=1(2.3 \%)$ \\
\hline \multicolumn{2}{|l|}{${ }^{1}$ Percentages add up to $100 \%$} \\
\hline \multicolumn{2}{|c|}{${ }^{2}$ Item scale: 1 ("very dissatisfied”) - 5 (“very satisfied”) } \\
\hline
\end{tabular}




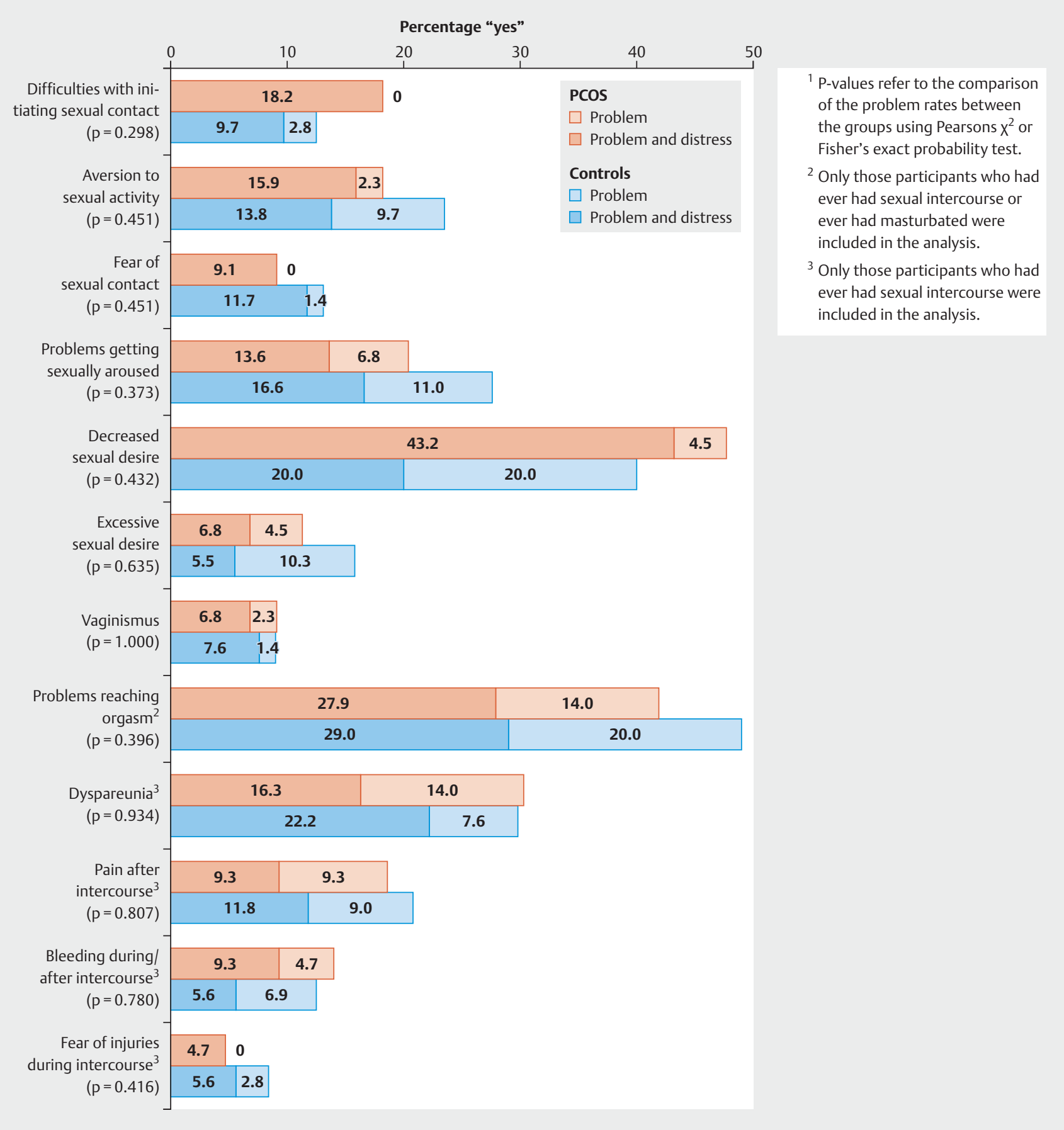

- Fig. 1 Sexual problems and dysfunctions: problem rates and distress.

4.00, missing $\mathrm{n}=5$; non-clinical controls: $\mathrm{Md}=3.0, \mathrm{Q}_{25}-$ $\mathrm{Q}_{75}=1.00-4.00$, missing $\mathrm{n}=12$ ).

\section{Standardised scales}

\section{Group comparisons}

A difference between women with PCOS and controls was revealed concerning total sexual function scores (FSFI). The PCOS sample showed significantly lower values $(\mathrm{t}[40]=-3.59$, $p \leq 0.001, r=0.49$ ). The comparison of feelings of inadequacy in social situations (FUSS social) also yielded a significant difference $(t[43]=1.80, p=0.015, r=0.36)$ indicating stronger insecurity in women with PCOS. For feelings of inadequacy in sexual situations a clear difference emerged $(t[43]=3.62, p \leq 0.001, r=0.48)$ again showing higher levels of discomfort in women with PCOS. Self-esteem ratings (RSE) were comparable to controls $(\mathrm{t}[40]=-0.25$, $\mathrm{p}=0.805, \mathrm{r}=0.04)$. The mean depression score (BSI t-score: Mean $[S D]=62.0$ [11.71]) almost reached the cut-off value for relevant clinical depression (t-score $\geq 63$ ). Please check $>$ Table 2 . 
- Table 2 Psychosexual variables, self-esteem and depression in PCOS: group comparisons.

\begin{tabular}{|c|c|c|c|c|c|}
\hline & $\begin{array}{l}\text { PCOS } \\
n=44\end{array}$ & $\begin{array}{l}\text { Comparison } \\
\text { samples }\end{array}$ & & \multicolumn{2}{|c|}{ PCOS vs. controls } \\
\hline & Mean (SD) & Mean (SD) & & \multicolumn{2}{|c|}{ t-tests } \\
\hline \multicolumn{6}{|c|}{ Female Sexual Function Index (FSFI) } \\
\hline Full-scale score ${ }^{2}$ & $27.5(5.33)$ & $30.5(5.29)$ & Rosen et al. [66] & $* * *$ & $t(40)=-3.59, p \leq 0.001, r=0.49$ \\
\hline " missing & $n=3$ & & & & \\
\hline \multicolumn{6}{|c|}{ Feelings of Inadequacy in Social and Sexual Situations (FUSS) ${ }^{3}$} \\
\hline Social insecurity - Scale 1 & $14.4(11.92)$ & $9.82(7.35)$ & Fahrner et al. [73] & * & $t(43)=2.54, p=0.015, r=0.36$ \\
\hline - missing & - & & & & \\
\hline Sexual insecurity - Scale 2 & $17.7(10.71)$ & $11.82(7.79)$ & Fahrner et al. [73] & $* * *$ & $t(43)=3.62, p \leq 0.001, r=0.48$ \\
\hline - missing & - & & & & \\
\hline \multicolumn{6}{|c|}{ Rosenberg Self-Esteem Scale (RSE) } \\
\hline Total Score ${ }^{4}$ & $30.9(5.73)$ & $31.1(4.55)$ & Martín-Albo et al. [77] & ns & $t(40)=-0.25, p=0.805, r=0.04$ \\
\hline - missing & $n=3$ & & & & \\
\hline \multicolumn{6}{|c|}{ Brief Symptom Inventory (BSI) Depression Scale } \\
\hline Mean t-score ${ }^{5}$ & $62.0(11.71)$ & - & Franke [69] & & \\
\hline - missing & - & & & & \\
\hline $\begin{array}{l}{ }^{1} \text { ns "not significant", * sig } \\
2 \text { Full scale scores are "poo } \\
{ }^{3} \text { High scores indicate high } \\
{ }^{4} \text { Items scaled: } 1 \text {-4, high sc } \\
{ }^{5} \text { t-scores standardization: }\end{array}$ & $\begin{array}{l}\text {-level of } 5 \%,{ }^{*} \\
3 \text {, as "good" or } \\
\text { security. } \\
\text { te high self-est } \\
=10 \text {; in the BSI }\end{array}$ & $\begin{array}{l}\text { ificant at } \alpha \text {-leve } \\
\text { factory" when }\end{array}$ & $\begin{array}{l}\%,{ }^{* * *} \text { significant at } \alpha-l e \\
n \text { the range of } 24-29 \text {, an }\end{array}$ & $\begin{array}{l}0.1 \% \\
\text { very ge }\end{array}$ & when $\geq 30[61,62]$. \\
\hline
\end{tabular}

\section{Categorisations}

With respect to the FSFI eight women (19.5\%) of the PCOS sample were categorised as having "poor" sexual function. As far as feelings of inadequacy in social situations (FUSS social) were concerned $n=11(25.0 \%)$ showed "critical" scores. Results are five times higher than expected in the general population. With regard to feelings of inadequacy in sexual situations (FUSS sexual) the score was "critical" in $8(18.2 \%)$ individuals. This is more than three times the expected rate. Only one person (2.4\%) was classified as having critically low self-esteem. The depression scale identified an extraordinarily high number of participants with a clinical depression: $n=24$ (54.4\%). Please check $•$ Table 3.

\section{Correlation matrix - standardised measures}

Sexual function showed negative correlations with feelings of inadequacy in social and even more so in sexual situations (FSFI \& FUSS social: $r=-0.37$; FSFI \& FUSS sexual: $r=-0.54$ ), whereas the two FUSS scales are highly interrelated (FUSS social \& FUSS sexual: $r=-0.75)$. Sexual function showed a negligible association with depression (FSFI \& BSI depression: $r=0.01$ ), but depression was considerably correlated with apprehension in social and sexual situations (BSI depression \& FUSS social: $r=0.40$; BSI depression \& FUSS sexual: $r=0.51$ ) and showed a strong correlation with selfesteem (BSI depression \& RSE: $r=-0.63$ ). Hirsutism showed a relevant association with FUSS social (FG \& FUSS social: $r=0.31$ ). Body mass index showed a positive medium-size correlation with sexual function (BMI \& FSFI: $r=0.32$ ). Age did not reach a medium size correlation with any of the scales, neither did the wish for a child. Please check $>$ Table 4.

\section{Content analysis}

Of the total number of 44 participants, 24 (54.5\%) commented on the question "If you have any of the sexual problems mentioned above, what do you think is/are the reason(s) for it?". Important themes that arose were related to psychological difficulties, the sexual experience, somatic conditions and partnership. Psychological difficulties such as "Low self-esteem" and "Feeling of being unattractive" were seen in 2 of 24 (8.3\%) women, respectively. "General emotional problems" were reported by 3 women (12.5\%). The section of Sexual experience yielded the "fear not to get pregnant" as a reason for sexual problems and "insufficient lubrication": these problems were each reported by 2 of 24 (8.3\%) women. Somatic conditions included "hormones" as reasons for sexual dysfunctions in $5(20.8 \%)$ participants. Issues related to "partner and relationship characteristics" were given as reasons by 6 of $24(25.0 \%)$ women in the section of Partnership. Please check $>$ Table 5 .

\section{Discussion}

The presented study assessed sexual quality of life in women with PCOS and was not restricted to sexual functioning. The impact of the diverse factors that were assessed are discussed in the following section. 
- Table 3 Psychosexual variables, self-esteem and depression in PCOS: Critical cases

\begin{tabular}{|c|c|c|c|}
\hline & & & PCOS \\
\hline & & & $\mathrm{n}=\mathbf{4 4}$ \\
\hline & Score & Category & n (\%) \\
\hline \multicolumn{4}{|c|}{ Female Sexual Function Index (FSFI) ${ }^{1}$} \\
\hline \multirow[t]{4}{*}{ Full-scale score } & $\leq 23$ & “poor” & $8(19.5)$ \\
\hline & $24-29$ & "satisfactory" & $15(36.6)$ \\
\hline & $\geq 30$ & “good” & $18(43.9)$ \\
\hline & missing & & $\mathrm{n}=3$ \\
\hline \multicolumn{4}{|c|}{ Feelings of Inadequacy in Social and Sexual Situations (FUSS) ${ }^{2}$} \\
\hline \multirow[t]{3}{*}{ Social insecurity - Scale 1} & $\leq 1.64$ & "average" & $33(75.0)$ \\
\hline & $>1.64$ & “critical” & $11(25.0)$ \\
\hline & missing & & - \\
\hline \multirow[t]{3}{*}{ Sexual insecurity - Scale 2} & $\leq 1.64$ & “average” & $36(81.8)$ \\
\hline & $>1.64$ & “critical” & $8(18.2)$ \\
\hline & missing & & - \\
\hline \multicolumn{4}{|c|}{ Rosenberg Self-Esteem Scale (RSE) ${ }^{3}$} \\
\hline \multirow[t]{3}{*}{ Total Score } & $<-1.64$ & “critical” & $1(2.4)$ \\
\hline & $\geq-1.64$ & “average" & $40(97.6)$ \\
\hline & missing & & $\mathrm{n}=3$ \\
\hline \multicolumn{4}{|c|}{ Brief Symptom Inventory (BSI) ${ }^{4}$ Depression Scale } \\
\hline \multirow[t]{3}{*}{ Mean t-score } & $<63$ & "average" & $20(45.5)$ \\
\hline & $\geq 63$ & “critical” & $24(54.5)$ \\
\hline & missing & & - \\
\hline \multicolumn{4}{|c|}{${ }^{1}$ Full scale scores are "poor" when $\leq 23$, as "good" or "satisfactory" when within the range of $24-29$, and as "very good" when $\geq 30[71,72]$. } \\
\hline \multicolumn{4}{|c|}{$\begin{array}{l}2 \text { High scores indicate high levels of anxiety, } z \text {-scores above } z=+1.64 \text { (FUSS social, FUSS sexual) were defined as "critical", in the general population only } 5 \% \\
\text { of the people would be expected to show scores above this cut-off value. }\end{array}$} \\
\hline \multicolumn{4}{|c|}{$\begin{array}{l}3 \text { High scores indicate high levels of self-esteem, scores below - } 1.64 \text { (RSE) were defined as "critical", for in the general population only } 5 \% \text { of the people } \\
\text { would be expected to show scores below this cut-off value. }\end{array}$} \\
\hline \multicolumn{4}{|c|}{${ }^{4}$ High scores indicate high levels of depression BSI t-scores $\geq 63$ are seen as clinically relevant [69]. } \\
\hline
\end{tabular}

- Table 4 Correlations.

\begin{tabular}{|c|c|c|c|c|c|}
\hline & FSFI & FUSS social & FUSS sexual & RSE & BSI depression \\
\hline FSFI & - & -0.367 & -0.536 & 0.187 & 0.007 \\
\hline FUSS social & & - & 0.753 & -0.393 & 0.398 \\
\hline FUSS sexual & & & - & -0.578 & 0.510 \\
\hline RSE & & & & - & -0.626 \\
\hline BSI depression & & & & & - \\
\hline Age & 0.038 & -0.086 & 0.074 & -0.084 & -0.139 \\
\hline Body Mass Index & 0.315 & -0.038 & -0.110 & -0.212 & 0.188 \\
\hline Wish for a child & 0.222 & -0.231 & -0.184 & -0.058 & 0.177 \\
\hline Ferriman-Gallwey Score & -0.177 & 0.308 & 0.288 & -0.166 & 0.214 \\
\hline
\end{tabular}


- Table 5 Subjective reasons for sexual problems.

\begin{tabular}{|c|c|c|c|}
\hline \multirow[t]{2}{*}{ Category } & Subcategory & n (\%) & Representative quote \\
\hline & & $\begin{array}{l}\mathrm{PCOS} \\
\mathrm{n}=\mathbf{2 4 ^ { * }}\end{array}$ & \\
\hline \multirow{4}{*}{$\begin{array}{l}\text { Psychological } \\
\text { difficulties }\end{array}$} & - Low self-esteem & $2(8.3)$ & "Low self-confidence" \\
\hline & - Feeling of being unattractive & $2(8.3)$ & "I am ashamed of the body hair, razor burn" \\
\hline & - Fear of rejection & $1(4.2)$ & $\begin{array}{l}\text { "Fear that he could find out about the PCOS, especially } \\
\text { the body hair", "fear of his lack of understanding" }\end{array}$ \\
\hline & - General emotional problems & $3(12.5)$ & "Psychological difficulties" \\
\hline \multirow[t]{2}{*}{$\begin{array}{l}\text { Sexual } \\
\text { experience }\end{array}$} & - Fear not to get pregnant & $2(8.3)$ & $\begin{array}{l}\text { "I have the feeling that I won't get pregnant anyway, } \\
\text { I think it's standing in the way" }\end{array}$ \\
\hline & - Insufficient lubrication & $2(8.3)$ & “Maybe l'm not wet enough" \\
\hline \multirow{3}{*}{$\begin{array}{l}\text { Somatic } \\
\text { conditions }\end{array}$} & - Hormones (e.g. birth control pill, postpartal) & $5(20.8)$ & "I think it's due to the anti-baby pill. But I can't say for sure" \\
\hline & - PCOS & $1(4.2)$ & "Because of the PCO Syndrome" \\
\hline & - General health problems & $1(4.2)$ & “Health issues" \\
\hline \multirow[t]{2}{*}{ Partnership } & - Partner and relationship characteristics & $6(25.0)$ & “My partner doesn't excite me any more" \\
\hline & - Stress, not enough time with partner & $3(12.5)$ & $\begin{array}{l}\text { "Different working hours between me and my partner, } \\
\text { stress" }\end{array}$ \\
\hline \multirow[t]{2}{*}{ Other } & - Have always had sexual dysfunction(s) & $2(8.3)$ & "I have always had problems, don't know it any other way." \\
\hline & - Don’t know & $3(12.5)$ & “?” \\
\hline
\end{tabular}

\section{Sexual functioning and sexual satisfaction}

Previous studies have found mixed results regarding sexual functioning. Some authors have reported impairment women with PCOS in certain areas like orgasm completion [32], genital pain $[29,35]$ or sexual desire $[30,31]$, but many studies have not found a significant reduction in overall sexual functioning $[24,27,28$, 32]. Taken together our study showed moderate impairment of sexual functioning. There was no impairment at the level of individual sexual problems according to the list of "sexual problems and dysfunctions", but the mean FSFI score was significantly lower than that of a comparison group. The group mean of the FSFI score was still within the "satisfactory" range (27.5 [5.33], compare - Table 2) but $19.5 \%$ showed a poor outcome when the scores were categorised (i.e. number of scores below 23). Bearing in mind that sexual dysfunctions are widespread in the population $[66,85-88]$ further studies are necessary to examine whether PCOS contributes to a higher prevalence of sexual dysfunctions.

This study found moderate sexual satisfaction in PCOS. Regarding sexual satisfaction, our sample with PCOS was less satisfied than a group of women with vaginal agenesis [89]. The results are in line with previous research that indicates a reduced sexual satisfaction in PCOS compared to controls $[16,24,34,35]$.

\section{Social and sexual insecurity}

To our knowledge, this study is the first that examined social and sexual insecurity in PCOS with a detailed questionnaire. The findings showed highly elevated insecurity in the PCOS sample compared to controls and the scores were notably correlated with the degree of body hair. Previous studies indicate that there are several psychological problems associated with hirsutism that can lead to the impairment of sexual well-being [44]. Hirsute women can feel inhibited, ashamed of their body hair and less feminine so that their sexual confidence is compromised [32, 37 , $54,90]$. Many hirsute women avoid certain social situations [ 43 , 47], and show stronger social fears [45, 47]. Women with PCOS feel less sexually attractive compared to controls [16] or before antiandrogen treatment [29]. Therefore, the presented results are in line with previous findings uncovering sizable associations between hirsutism and feelings of insecurity. Taking a closer look at the two subscales of feelings of inadequacy in "social" vs. "sexual" situations, our participants with PCOS showed higher anxiety in the social domain. A different picture is seen in women with vaginal agenesis where the bodily condition is not visible to the naked eye. These women report higher distress in sexual compared to social situations [89]. These aspects of sexual quality of life are important to the sexual experience but are an area that remains uncovered when only focussing on sexual dysfunctions.

\section{Self-esteem}

Keegan et al. found higher self-esteem in women with PCOS using the RSE, but the sample was skewed towards the better in sociodemographical terms [44]. DeNiet et al. found lower self-esteem using the same scale, yet, a large sample size might have led to a significant result [20]. In this study women with PCOS did not differ from controls regarding RSE results. This contradicts the outcomes of qualitative studies [30,37, 54]. The RSE assesses a global level of self-worth. In order to detect PCOS-related problems, 
questionnaires might have to be more focussed on specific areas of body image and sexual confidence [4-7].

\section{Depression}

Depression is an important mediator of sexuality in women. This study found depression in more than half of the women with PCOS (54.5\%). High rates have also been reported by other authors [17, 24, 36, 51, 57, 91], but not all [27]. Tan et al. found a rate of about $50 \%$ with at least a mild depression [91], Pastore et al. found $40-60 \%$ in a PCOS cohort [58]. These numbers are comparable with the result of this study. The point prevalence of depression in Germany is 5.6\% [92]. Studies reporting lower levels might be biased in that they excluded participants with any prior psychiatric diagnosis or current use of psychiatric medication [27, 34].

The results suggest that enormous rates of depression can be expected in PCOS. Depression can thus be seen as an important contributor to impaired sexual quality of life in PCOS and should also always be considered as a treatment focus apart from gynaecological, endocrinological and sexological care.

\section{Body weight}

While the literature presents a clear picture of the inverse relationship between body weight and sexual function $[93,94]$ the situation is less clear in women with PCOS [26,41,42]. For instance, Ferraresi et al. presented a study showing FSFI scores in the low functioning range in obese women without PCOS while women with PCOS showed borderline scores irrespective of weight status [26]. In this study, unexpectedly, a positive correlation between body weight and sexual function was found. As obesity is only one factor that can contribute to the sexual experience it seems that other parameters might be overshadowing body weight effects in PCOS.

\section{Wish for a child}

The intensity of the "wish for a child" did not show any substantial correlations with the main outcome measures. This might be an effect of the two roads infertile couples can take: Infertility might put strain on the partnership [48-51] or lead to an intensified sense of belonging $[33,91]$.

\section{Limitations}

The study is based on self-report and did not include expert ratings or physical examinations. Data on hormonal levels would have allowed the authors to gain more insight into the data, yet, as Caruso and colleagues suggested psychological and social factors might indeed be overriding hormonal effects in PCOS [29]. A problem with PCOS is the heterogeneous clinical picture that makes it difficult to attribute research findings to one common feature. In future studies more homogenous subgroups could be selected.

The sample size is rather small and the sampling routes might have caused biased results. Therefore, the results cannot be generalised to the whole population of women with PCOS. The participants were largely informed about the study via fertility clinics which most certainly affects sexual activity and partnership rates [95]. For instance feelings of insecurity and the fear of being re- jected might be much more pronounced in samples with lower partnership rates. These fears might even stop women from engaging in social and sexual encounters and lower their chance of positive experiences. Recently, differences in medical (e.g. cycle length) and lifestyle measures have been reported in women with PCOS who had children vs. no children [96]. Depression might exacerbate these difficulties by typical cognitions as a negative view on the self and a pessimistic view on the world. These effects and mutually reinforcing mechanisms should be investigated in further quantitative and qualitative studies.

Some strong points of this study are that the investigation was not confined to the assessment of global scores of sexual function, but especially included the assessment of feelings of inadequacy in social and sexual situations and single sexual problems.

Several standardised scales were included to ensure comparability and correlations between them were analysed to reveal associations. The study was not conducted within a treatment setting, so common social desirability effects could be minimised.

\section{Conclusion}

While sexual function per se is only partly impaired, feelings of inadequacy in social and sexual situations are frequent and considerably correlated with the degree of hirsutism in women with PCOS and constitute a major problem in their sexual quality of life. The issue of sexuality should be openly addressed with the patients in order to reduce feelings of shame and inhibition. Unfortunately, sexual counselling is still not a standard procedure in hospital and outpatient care, as special training is needed for doctors and psychologists. If the screening for sexual problems is positive, the patient should be offered to talk to their attending gynaecologist, see a psychologist or be referred to a specialist if problems are severe. A more widespread acknowledgement of the importance of sexual quality of life and the integration of "sexual counselling" into academic curricula might help to improve the treatment situation.

A main issue in women with PCOS is depression. All patients with PCOS should be screened for socio-sexual difficulties and emotional problems. Gynaecologists can ask for problems during the exploration or for instance use short questionnaires for the screening for depression. If the screening is positive patients should be referred to a psychiatrist or psychotherapist.

Interdisciplinary cooperation should be fostered and targeted interventions for the treatment of hirsutism and specialised psychological and sexological counselling should be offered in order to optimise patient care.

\section{Acknowledgements}

The authors would like to thank the participants for their time and interest in taking part in the study. The research project was kindly supported by the Else Kröner-Fresenius Stiftung.

\section{Conflict of Interest}

The authors declare that they have no conflict of interest. 


\section{References}

[1] Arrington R, Cofrancesco J, Wu AW. Questionnaires to measure sexual quality of life. Qual Life Res 2004; 13: 1643-1658

[2] Mölleken D, Richter-Appelt H, Stodieck S et al. Influence of personality on sexual quality of life in epilepsy. Epileptic Disord 2010; 12: 125-132

[3] Schönbucher V. Sexuelle Zufriedenheit von Frauen: Psychosoziale Faktoren. Zeitschrift für Sexualforschung 2007; 20: 21-41

[4] Berman LA, Berman J, Miles $M$ et al. Genital self-image as a component of sexual health: Relationship between genital self-image, female sexual function, and quality of life measures. J Sex Marital Ther 2003; 29 (Suppl.): 11-21

[5] Berman L, Windecker MA. The relationship between women's genital self-image and female sexual function: A national survey. Curr Sex Health Rep 2008; 5: 199-207

[6] Zielinski R, Miller J, Low KL et al. The relationship between pelvic organ prolapse, genital body image, and sexual health. Neurol Urodynam 2012; 31: 1145-1148

[7] Woertman L, van den Brink F. Body image and female sexual functioning and behavior: a review. J Sex Res 2012; 49: 184-211

[8] Carmina E, Rosato F, Janni A et al. Relative prevalence of different androgen excess disorders in 950 women referred because of clinical hyperandrogenism. J Clin Endocrinol Metab 2006; 91: 2-6

[9] Franks S. Polycystic ovary syndrome. N Engl J Med 1995; 333: 853-861

[10] Hart R, Hickey M, Franks S. Definitions, prevalence and symptoms of polycystic ovaries and polycystic ovary syndrome. Best Pract Res Clin Ob 2004; 18: 671-683

[11] Conway G, Dewailly D, Diamanti-Kandarakis E et al. The polycystic ovary syndrome: A position statement from the European Society of Endocrinology. Eur J Endocrinol 2014; 171: P1-P29

[12] Knochenhauer ES, Key TJ, Kahsar-Miller $M$ et al. Prevalence of the polycystic ovary syndrome in unselected black and white women of the southeastern United States: a prospective study. J Clin Endocrinol Metab 1998; 83: 3078-3082

[13] Azziz R, Woods KS, Reyna R et al. The prevalence and features of the polycystic ovary syndrome in an unselected population. J Clin Endocrinol Metab 2004; 89: 2745-2749

[14] March WA, Moore VM, Willson KJ et al. The prevalence of polycystic ovary syndrome in a community sample assessed under contrasting diagnostic criteria. Hum Reprod 2010; 25: 544-551

[15] Coffey S, Mason H. The effect of polycystic ovary syndrome on healthrelated quality of life. Gynecol Endocrinol 2003; 17: 379-386

[16] Elsenbruch S, Hahn S, Kowalsky D et al. Quality of life, psychosocial wellbeing, and sexual satisfaction in women with polycystic ovary syndrome. J Clin Endocrinol Metab 2003; 88: 5801-5807

[17] Jauca R, Jäger S, Franke GH. Psychische Belastung, Lebenszufriedenheit und Krankheitsverarbeitung bei Frauen mit dem Polyzystischen Ovarsyndrom (PCOS). Z Med Psychol 2010; 19: 38-47

[18] Jedel E, Waern M, Gustafson D et al. Anxiety and depression symptoms in women with polycystic ovary syndrome compared with controls matched for body mass index. Hum Reprod 2010; 25: 450-456

[19] Jones GL, Hall JM, Balen AH et al. Health-related quality of life measurement in women with polycystic ovary syndrome: a systematic review. Hum Reprod 2008; 14: 15-25

[20] de Niet JE, de Koning CM, Pastoor $\mathrm{H}$ et al. Psychological well-being and sexarche in women with polycystic ovary syndrome. Hum Reprod 2010; 25: 1497-1503

[21] Schmid J, Kirchengast S, Vytiska-Binstorfer E et al. Infertility caused by PCOS - health-related quality of life among Austrian and Moslem immigrant women in Austria. Hum Reprod 2004; 19: 2251-2257
[22] Trent ME, Rich M, Austin SB et al. Quality of life in adolescent girls with polycystic ovary syndrome. Arch Pediat Adol Med 2002; 156: 556-560

[23] Aloulou J, Halouani N, Charfeddine F et al. Marital sexual satisfaction in women with polycystic ovary syndrome. Eur Psychiat 2012; 27: 1

[24] Månsson M, Norström K, Holte J et al. Sexuality and psychological wellbeing in women with polycystic ovary syndrome compared with healthy controls. Eur J Obstet Gynecol Reprod Biol 2011; 155: 161-165

[25] Drosdzol A, Skrzypulec V, Mazur B et al. Quality of life and marital sexua satisfaction in women with polycystic ovary syndrome. Folia Histochem Cyto 2007; 45 (Suppl. 1): 93-97

[26] Ferraresi SR, da Silva Lara LA, Reis RM et al. Changes in sexual function among women with polycystic ovary syndrome: a pilot study. J Sex Med 2013; 10: 467-473

[27] Battaglia C, Nappi RE, Mancini F et al. PCOS, sexuality, and clitoral vascularisation: a pilot study. J Sex Med 2008; 5: 2886-2894

[28] Veras AB, Bruno RV, de Avila MAP et al. Sexual dysfunction in patients with polycystic ovary syndrome: clinical and hormonal correlations. Compr Psychiat 2011; 52: 486-489

[29] Caruso S, Rugolo S, Agnello C et al. Quality of sexual life in hyperandrogenic women treated with an oral contraceptive containing chlormadinone acetate. J Sex Med 2009; 6: 3376-3384

[30] Jones GL, Hall JM, Lashen HL et al. Health-related quality of life among adolescents with polycystic ovary syndrome. J Obstet Gynecol Neonatal Nurs 2011; 40: 577-588

[31] Conaglen HA, Conaglen JV. Sexual desire in women presenting for antiandrogen therapy. J Sex Marital Ther 2003; 29: 255-267

[32] Stovall DW, Scriver JL, Clayton AH et al. Sexual function in women with polycystic ovary syndrome. I Sex Med 2012; 9: 224-230

[33] Hahn S, Benson S, Elsenbruch S et al. Metformin treatment of polycystic ovary syndrome improves health-related quality-of-life, emotional distress and sexuality. Hum Reprod 2006; 21: 1925-1934

[34] Elsenbruch S, Benson S, Hahn S et al. Determinants of emotional distress in women with polycystic ovary syndrome. Hum Reprod 2006; 21: 1092-1099

[35] Hahn S, Janssen OE, Tan S et al. Clinical and psychological correlates of quality of life in polycystic ovary syndrome. Eur J Endocrinol 2005; 153 : 853-860

[36] Himelein M], Thatcher SS. Depression and body image among women with polycystic ovary syndrome. J Health Psych 2006; 11: 613-625

[37] Kitzinger C, Willmott ]. "The thief of womanhood”: women's experience of polycystic ovarian syndrome. Soc Sci Med 2002; 54: 349-361

[38] Zawadski ], Dunaif A. Diagnostic Criteria for polycystic Ovary Syndrome: towards a rational Approach. In: Dunaif A, ed. Polycystic Ovary Syndrome. Boston: Blackwell Scientific; 1992: 377-384

[39] The Rotterdam ESHRE/ASRM-Sponsored PCOS Consensus Workshop Group. Revised 2003 consensus on diagnostic criteria and long-term health risks related to polycystic ovary syndrome. Fertil Steril 2004; 81 : $19-25$

[40] Goodman NF, Cobin RH, Futterweit W et al. American Association of Clinical Endocrinologists, American College of Endocrinology, and Androgen Excess and PCOS Society disease state clinical review: Guide to the best practices in the evaluation and treatment of Polycystic ovary syndrome - part 2. Endoc Pract 2015; 21: 1415-1426

[41] Albani F, Santamaria V, Tonani S et al. Sexual function in lean and obese women with policystyc ovarian syndrome (PCOS). J Sex Med 2009; 6: 394

[42] Gateva A, Kamenov Z. Sexual function in bulgarian patients with PCOS and/or obesity before and after metformin treatment. J Sex Med 2011; 8: 381

[43] Barth JH, Catalan J, Cherry CA et al. Psychological morbidity in women referred for treatment of hirsutism. J Psychosom Res 1993; 37: 615-619 
[44] Keegan A, Liao LM, Boyle M. 'Hirsutism': a psychological analysis. J Health Psychol 2003; 8: 327-345

[45] Sonino N, Fava GA, Mani E et al. Quality of life of hirsute women. Postgrad Med J 1993; 69: 186-189

[46] Dennerstein L, de Senarclens M. The young woman: psychosomatic aspects of obstetrics and gynaecology. 7th International Congress on Psychosomatic Obstetrics and Gynaecology; 1983 Sep11-15, Dublin, Ireland. Amsterdam: Excerpta Medica; 1983

[47] Lipton MG, Sherr L, Elford J et al. Women living with facial hair: the psychological and behavioral burden. J Psychosom Res 2006; 61: 161-168

[48] Coëffin-Driol C, Giami A. The impact of infertility and its treatment on sexual life and marital relationships: review of the literature. Gynecol Obstet Fertil 2004; 32: 624-637

[49] Drosdzol A, Skrzypulec V. Evaluation of marital and sexual interactions of Polish infertile couples. J Sex Med 2009; 6: 3335-3346

[50] Tao P, Coates R, Maycock B. The impact of infertility on sexuality: a literature review. Australas Med J 2011; 4: 620-627

[51] Barnard L, Ferriday D, Guenther N et al. Quality of life and psychological well being in polycystic ovary syndrome. Hum Reprod 2007; 22: 22792286

[52] Larson JH, Anderson SM, Holman TB et al. A longitudinal study of the effects of premarital communication, relationship stability, and self-esteem on sexual satisfaction in the first year of marriage. I Sex Marital Ther 1998; 24: 193-206

[53] Cash TF. Women's Body Images. In: Wingood GM, DiClemente R], eds. Handbook of Women's sexual and reproductive Health. New York: Kluwer Academic/Plenum Publishers; 2002: 175-194

[54] Snyder BS. The lived experience of women diagnosed with polycystic ovary syndrome. J Obst Gyn Neonat Nurs 2006; 35: 385-392

[55] Bancroft J, Loftus J, Long JS. Distress about sex: a national survey of women in heterosexual relationships. Arch Sex Behav 2003; 32: 193208

[56] Basson R, Leiblum S, Brotto L et al. Revised definitions of women's sexual dysfunction. J Sex Med 2004; 1: 40-48

[57] Weiner CL, Primeau M, Ehrmann DA. Androgens and mood dysfunction in women: comparison of women with polycystic ovarian syndrome to healthy controls. Psychosom Med 2004; 66: 356-362

[58] Pastore LM, Patrie JT, Morris WL et al. Depression symptoms and body dissatisfaction association among polycystic ovary syndrome women. J Psychosom Res 2011; 71: 270-276

[59] Annagür BB, Tazegül A, Uguz F et al. Biological correlates of major depression and generalized anxiety disorder in women with polycystic ovary syndrome. J Psychosom Res 2013; 74: 244-247

[60] Cesta CE, Månsson M, Palm C et al. Polycystic ovary syndrome and psychiatric disorders: co-morbidity and heritability in a nationwide Swedish cohort. Psychoneuroendocrinology 2016; 73: 196-203

[61] American Psychiatric Association. Diagnostic and statistical Manual of mental Disorders. 4th ed., text revision. Washington: American Psychiatric Association; 2000

[62] Schönbucher V, Schweizer K, Rustige L et al. Sexual quality of life of individuals with 46,XY disorders of sex development. J Sex Med 2012; 9: 3154-3170

[63] Schönbucher V, Schweizer K, Richter-Appelt H. Sexual quality of life of individuals with Disorders of Sex Development and a 46,XY karyotype: a review of international research. J Sex Marital Ther 2010; 36: 193-215

[64] Schweizer K, Richter-Appelt H. Die Hamburger Studie zur Intersexualität. In: Schweizer K, Richter-Appelt H, Hrsg. Intersexualität kontrovers. Grundlagen, Erfahrungen, Positionen. 1. Aufl. Gießen: Psychosozial-Verlag; 2012: 187-205
[65] Rustige L. Validierung der Fragebögen zur Zufriedenheit mit den einzelnen Körperteilen (Körperpuppe) und zu sexuellen Schwierigkeiten und Verhaltensweisen (SVS): Erhebung einer Kontrollgruppe zur Erforschung des Körpererlebens und der Sexualität bei erwachsenen intersexuellen Menschen [Dissertation]. Hamburg: Staats- und Universitätsbibliothek Carl von Ossietzky; 2009

[66] Rosen CB. The Female Sexual Function Index (FSFI): A multidimensional self-report instrument for the assessment of female sexual function. J Sex Marital Ther 2000; 26: 191-208

[67] Gray-Little B, Williams VSL, Hancock TD. An Item Response Theory analysis of the Rosenberg Self-Esteem scale. Pers Soc Psychol B 1997; 23: 443-451

[68] von Collani G, Herzberg PY. Eine revidierte Fassung der deutschsprachigen Skala zum Selbstwertgefühl von Rosenberg. Z Diff Diagn Psychol 2003; 24: 3-7

[69] Franke GH. Brief Symptom Inventory von L. R. Derogatis (Kurzform der SCL-90-R) Deutsche Version-BSI: Manual. Göttingen: Beltz Test; 2000

[70] Berner MM, Kriston L, Zahradnik HP et al. Überprüfung der Gültigkeit und Zuverlässigkeit des deutschen Female Sexual Function Index (FSFI-d). Geburtsh Frauenheilk 2004; 64: 293-303

[71] Allen LM, Lucco KL, Brown CM et al. Psychosexual and functional outcomes after creation of a neovagina with laparoscopic Davydov in patients with vaginal agenesis. Fertil Steril 2010; 94: 2272-2276

[72] Fedele L, Bianchi S, Frontino $G$ et al. The laparoscopic Vecchietti's modified technique in Rokitansky syndrome: anatomic, functional, and sexual long-term results. Am J Obstet Gynecol 2008; 198: 377.e1-377.e6

[73] Fahrner EM. Selbstunsicherheit bei Patienten mit funktionellen Sexualstörungen: Ein Fragebogen zur Diagnostik. Mitteilungen der Gesellschaft fuer praktische Sexualmedizin 1984; 4: 15-16

[74] Rosenberg M. The Measurement of Self-esteem. In: Rosenberg M, ed. Society and the adolescent Self-image. Princeton: Princeton University Press; 1965: 16-36

[75] Blascovich J, Tomaka J. Measures of Self-esteem. In: Robinson JP, Shaver PR, Wrightsman LS, eds. Measures of Personality and social psychological Attitudes. San Diego: Academic Press, Elsevier Science; 1991: 115160

[76] Roth M, Decker O, Herzberg PY et al. Dimensionality and norms of the Rosenberg Self-esteem scale in a German general population sample. Eur J Psychol Assess 2008; 24: 190-197

[77] Martín Albo L, Núňez JL, Navarro JG et al. The Rosenberg Self-esteem scale. Span J Psychol 2007; 10: 458-467

[78] Derogatis LR, Melisaratos N. The Brief Symptom Inventory: an introductory report. Psychol Med 1983; 13: 595-605

[79] Hatch R, Rosenfield RL, Kim MH et al. Hirsutism: implications, etiology, and management. Am J Obstet Gynecol 1981; 140: 815-830

[80] Ferriman D, Gallwey JD. Clinical assessment of body hair growth in women. J Clin Endocrinol Metab 1961; 21: 1440-1447

[81] Azziz R, Carmina E, Sawaya ME. Idiopathic Hirsutism. Endocr Rev 2000; 21: $347-362$

[82] Azziz R, Carmina E, Dewailly D et al. The Androgen Excess and PCOS Society criteria for the polycystic ovary syndrome: the complete task force report. Fertil Steril 2009; 91: 456-488

[83] Field A. Discovering Statistics using SPSS, 3rd ed. London: Sage Publications; 2009

[84] Mayring P. Einführung in die qualitative Sozialforschung. München: Psychologische Verlagsunion; 1990

[85] Anastasiadis AG, Davis AR, Ghafar MA et al. The epidemiology and definition of female sexual disorders. World J Urol 2002; 20: 74-78

[86] Domoney C. Sexual function in women: what is normal? Int Urogynecol ] 2009; 20: 9-17 
[87] Laumann EO, Paik A, Rosen RC. Sexual dysfunction in the United States prevalence and predictors. JAMA 1999; 281: 537-544

[88] Nicolosi A, Laumann EO, Glasser DB et al. Sexual behavior and sexual dysfunctions after age 40: the global study of sexual attitudes and behaviors. Urology 2004; 64: 991-997

[89] Fliegner M, Krupp K, Brunner F et al. Sexual Life and Sexual Wellness in Individuals with Complete Androgen Insensitivity Syndrome (CAIS) and Mayer-Rokitansky-Küster-Hauser Syndrome (MRKHS). J Sex Med 2014; 11: 729-742

[90] Krupp K, Brunner F, Fliegner $M$ et al. Fragebogen zum Erleben der eigenen Weiblichkeit (FB-W): Ergebnisse von Frauen mit Mayer-RokitanskyKüster-Hauser Syndrom und Frauen mit polyzystischem Ovarsyndrom. Psychother Psych Med 2013; 63: 334-340

[91] Tan S, Hahn S, Benson S et al. Psychological implications of infertility in women with polycystic ovary syndrome. Hum Reprod 2008; 23: 20642071
[92] Jacobi F, Klose M, Wittchen HU. Psychische Störungen in der deutschen Allgemeinbevölkerung: Inanspruchnahme von Gesundheitsleistungen und Ausfalltage. Bundesgesundheitsbl - Gesundheitsforsch - Gesundheitsschutz 2004; 47: 736-744

[93] Kocełak P, Chudek J, Naworska B et al. Psychological disturbances and quality of life in obese and infertile women and men. Int J Endocrinol 2012; 2012: 1-14

[94] Kolotkin RL, Zunker C, Østbye T. Sexual functioning and obesity: a review. Obesity 2012; 20: 2325-2333

[95] Wischmann T, Schilling K, Toth B et al. Sexuality, self-esteem and partnership quality in infertile women and men. Geburtsh Frauenheilk 2014; 74: 759-7 63

[96] Stassek J, Ohnolz F, Hanusch Y et al. Do pregnancy and parenthood affect the course of PCO Syndrome? Initial results from the LIPCOS study (Lifestyle Intervention for Patients with Polycystic Ovary Syndrome [PCOS]). Geburtsh Frauenheilk 2015; 75: 1153-1160 